\title{
Relationships between sex ratio, climate and density in red deer: the importance of spatial scale
}

\author{
ATLE MYSTERUD*, NIGEL G. YOCCOZ*†, NILS CHR. STENSETH* \\ and ROLF LANGVATN† \\ *Department of Biology, Division of Zoology, University of Oslo, PO Box 1050 Blindern, N-0316 Oslo, \\ Norway, (atle.mysterud@bio.uio.no); †Department of Arctic Ecology, Norwegian Institute for Nature Research \\ (NINA), Polar Environmental Centre, N-9296 Tromsø, Norway; and †University Studies at Svalbard (UNIS), \\ N-9170 Longyearbyen, Spitsbergen, Norway
}

\begin{abstract}
Summary
1. Recently, contrasting evidence of density-dependent offspring sex ratio variation in red deer (Cervus elaphus L.) has been presented. Kruuk et al. (1999) reported that the proportion of male red deer born on the island of Rum, Scotland, each year declined with increasing population density and with winter rainfall, i.e. as nutritional stress in females increased. In contrast, Post et al. (1999a) reported increasing male-biased offspring sex ratios in Hordaland, Norway, with both rising numbers of hinds and increasing values of the North Atlantic Oscillation (NAO), which they regarded an index of severe winters.
\end{abstract}

2. Compared to Post et al. (1999a), we reanalysed sex ratio variation on a greatly extended data set, including four populations of Norwegian red deer, taking into account a finer population substructure.

3. The proportion of male calves shot each autumn declined markedly as density increased in all four populations. The proportion of male calves shot each autumn increased significantly with an increasing NAO index in one of the four populations, but there was no residual effect of the NAO once the effect of snow depth (at low elevation) was controlled for (decreasingly male biased harvest with increasing snow depth).

4. At the west coast of Norway, the NAO is positively correlated with temperature and precipitation. However, since temperatures in this region often are around $0{ }^{\circ} \mathrm{C}$ during winter, the relationship between the NAO and snow depth may be difficult to predict.

5. An analysis of variation in snow depth revealed that snow depth was negatively correlated with the NAO at low altitudes (below $400 \mathrm{~m}$ ), but this relationship was reversed at high altitudes giving a positive correlation between snow depth and the NAO. We therefore suggest that a high NAO index indicates favourable winter conditions for red deer, as red deer winter at low altitude, and since recent studies show that a high index of the NAO is generally positively correlated with body weight in red deer.

6. Female red deer thus reared fewer sons as nutritional stress increased with increasing density and severity of climate in Norway, which is consistent with the birth sex ratios observed on Rum, Scotland.

Key-words: Cervus elaphus, density dependence, extrinsic modification hypothesis, North Atlantic Oscillation, ungulates.

Journal of Animal Ecology (2000) 69, 959-974

Correspondence: Dr Atle Mysterud, Department of Biology, Division of Zoology, University of Oslo, PO Box 1050 Blindern, N-0316 Oslo, Norway. Tel.: + 47228540 45; Fax: + 47228546 05; E-mail: atle.mysterud@ bio.uio.no 
Red deer sex ratio and spatial scale

(C) 2000 British Ecological Society Journal of Animal Ecology, 69, 959-974
Several studies have reported biased offspring sex ratios in mammals (reviews in Williams 1979; Clutton-Brock \& Iason 1986; Clutton-Brock 1991; Hewison \& Gaillard 1999). Adaptive manipulation of the birth-sex ratio may be expected when costs and/or benefits differ for production of either sex. Trivers \& Willard (1973) proposed that in species in which the variance in male reproductive success exceeds that of females, additional parental investment would benefit sons more than daughters, provided that offspring reproductive success is determined by phenotypic quality and that phenotypic quality in turn is determined by the level of maternal care during the juvenile stage (Maynard Smith 1980). Ungulates are regarded as ideal candidates for testing mechanisms regarding adaptive sex ratio variation (Hewison \& Gaillard 1999), since most ungulates are sexually dimorphic in body size (Weckerly 1998; Loison et al. 1999a), with male breeding success dependent on fighting ability and body size (Clutton-Brock, Guinness \& Albon 1982). In addition, ungulates are iteroparous and usually produce only one (or two) young per litter. Ungulates are also generally polygynous, so variance in reproductive success might be greater among males than among females (Hewison \& Gaillard 1999).

However, offspring sex ratio variation in ungulates appears notoriously inconsistent among studies (Festa-Bianchet 1996; Hewison \& Gaillard 1999; Hewison et al. 1999; Kruuk et al. 1999). This may be because more than one mechanism affects the sex ratio, and the action of these mechanisms depends on environmental conditions (Kruuk et al. 1999). Given the extensive body of evidence for relationships between maternal condition and offspring sex ratios in mammals at the individual level (CluttonBrock \& Iason 1986; Skogland 1986; Cameron et al. 1999), it is plausible that all extrinsic factors affecting body condition, such as population density and climate, also may affect offspring sex ratio at a population level (Kruuk et al. 1999; Post et al. 1999a). Variation in population density and climate is over short time scales. It is therefore likely that selection may not act to change the relationship between body condition and sex ratio which was adaptive for the individual at stable conditions, and hence, it is plausible that the individual response may be evident also at the population scale. Recently, contrasting findings of extrinsic modification of sex ratio by density and climate were reported for red deer (Cervus elaphus L.) (Kruuk et al. 1999; Post et al. 1999a). Kruuk et al. (1999) reported that the proportion of males born each year declined with increasing population density and winter rainfall, i.e. as nutritional stress in females increased, whereas Post et al. (1999a) reported increasingly male-biased offspring sex ratios at 3-5 months of age with rising numbers of hinds and a high index for the North Atlantic Oscillation (NAO), which they argued indicated increasingly severe winters, i.e. supposedly as nutritional stress in females decreased. Post et al. (1999a) suggested that females in poor condition may produce more sons, since poor-quality sons may nevertheless survive better than poor-quality daughters. However, empirical evidence in Norwegian red deer suggests that 'poor sons' have lower survival than 'poor daughters' (Loison et al. 1999).

The result of Post et al. (1999a) is surprising if we assume that female red deer in poor condition produce fewer sons as is expected in sexually dimorphic ungulates since they meet the assumption of the Trivers \& Willard (1973) model. Post et al. (1999a) used a pooled set of harvest data on red deer from two large counties in Norway (Rogaland and Hordaland), with significant local variation in red deer density and dynamics, as well as in local weather conditions across the area. The latter is due to the pronounced mountainous topography of the region, whereas the marked increase in total harvest within this region is a result of both increased density and range expansion (Fig. 1). Also, the management practice (i.e. hunting licenses issued) varied in time and space across this area. The choice of spatial scale may be crucially important when studying density dependence (Ray \& Hastings 1996; Donalson \& Nisbet 1999). It has been demonstrated that local population density was more important than total population density in influencing calf winter survival on the island of Rum, Scotland (Coulson et al. 1997), and scale-dependent population dynamics were also demonstrated for Soay sheep (Ovis aries L.) on Hirta in the St. Kilda archipelago (Coulson et al. 1999). Here we reanalyse sex ratio variation in Norwegian red deer on a greatly extended data set at a finer spatial scale (municipality scale), and assess whether the contrasting conclusions of Post et al. (1999a) and Kruuk et al. (1999), may be due to Post et al. (1999a) performing the analysis with less attention to the possible heterogeneity of subpopulations within the study area.

\section{Material and methods}

\section{RED DEER DATA}

The study area is the western part of southern Norway, which is the main area inhabited by red deer in Norway (Langvatn et al. 1996). Hunting data are recorded by wildlife boards and compiled at the Statistical Bureau of Norway (Statistics Norway 197798), from where the actual harvest data were retrieved. Generally, red deer may only be shot between 10 September and 15 November, but between these dates the actual hunting period varies slightly between counties. Red deer hunting in Nor- 


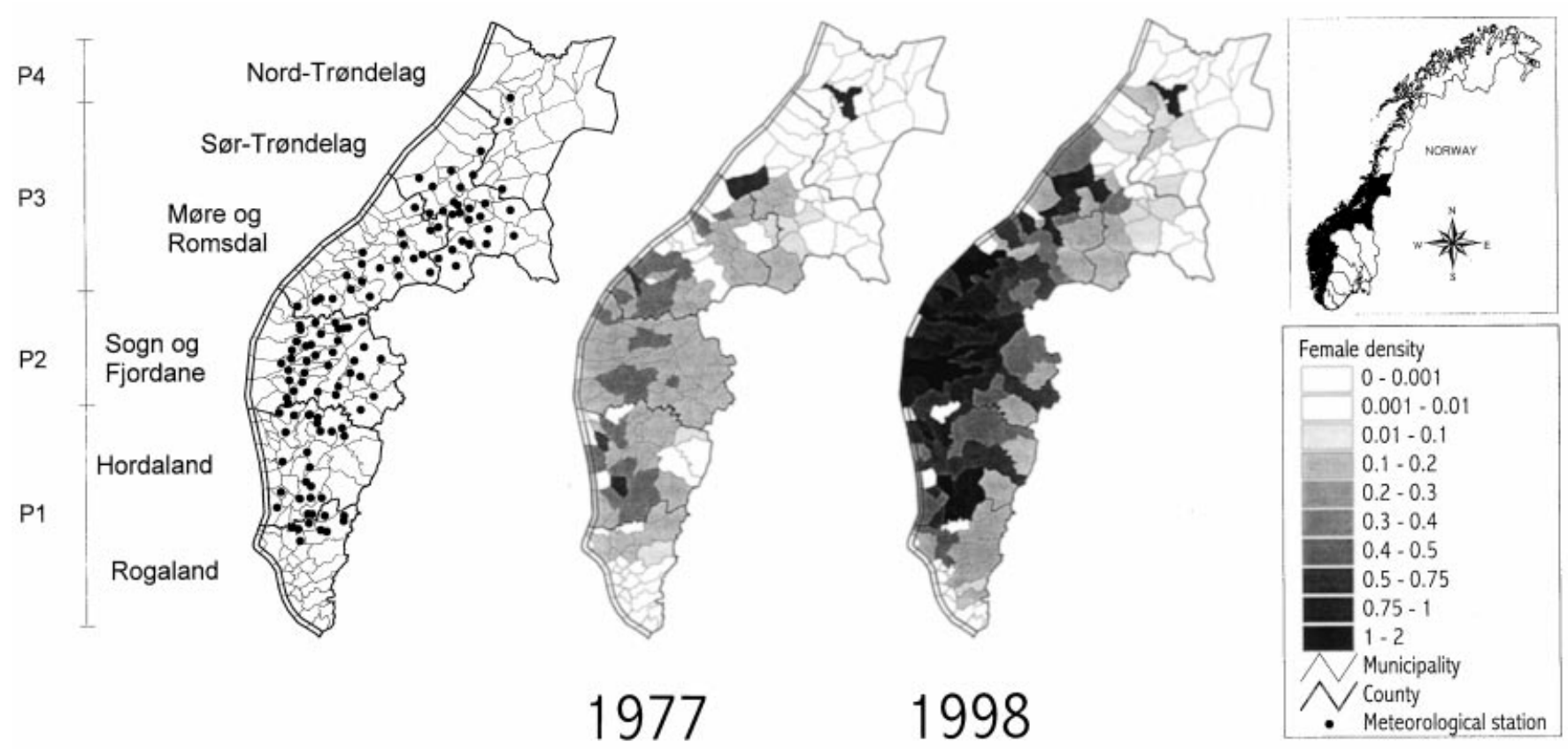

Fig. 1. Geographic location of the study area in Norway, the meteorological stations used, and an index of female density, calculated as number of adult ( $\geq 1$ years) females shot divided by the counting area (see text), in 1977 and 1998. Note that what is referred to as the Hordaland population in Post et al. (1999a) is P1.

(C) 2000 British

Ecological Society Journal of Animal Ecology, 69, 959-974 way are controlled through licenses issued by wildlife boards in each municipality. The number of licences issued is supposed to reflect range quality, areas of suitable habitat, and population status within the municipalities. Consequently, variation in management measures are likely to affect red deer populations at the scale of municipality rather than at the county level. From the hunting statistics we extracted data on number of male and female calves (age 3-5 months) shot each year (total 47762; Appendix) at the scale of municipality in the counties Rogaland, Hordaland, Sogn og Fjordane, Møre og Romsdal, Sør-Trøndelag and Nord-Trøndelag in Norway. To obtain an index for local population density, we divided the number of adult females $(\geq$ 1 years) shot each year by the so-called 'counting area' in each municipality (figures for counting area in 1997 was used for all years; Statistics Norway 1977-98; Fig. 1). The 'counting area' is the area of suitable red deer habitat within each municipality, constituting the basis for harvest quotas as approved by the management authorities. We hereafter refer to Rogaland and Hordaland as P1 (see Post et al. 1999a), Sogn og Fjordane as P2, Møre og Romsdal and Sør-Trøndelag as P3 and Nord-Trøndelag as P4 (Fig. 1) after Forchhammer et al. (1998). The justification for this division is partly geographical barriers like fjords and mountain ranges, and partly phytogeographical and climatic characteristics. Separate analyses were conducted for each of these four populations (Table 1, see details below).
Valuable observations with regard to sex ratio variation may come out of the analysis of harvest data (Post et al. 1999a), since mortality in red deer during their first summer appears to be sex-biased only in populations exposed to large predators such as bears (Smith \& Anderson 1996). No large predator exists at present in the area considered in this paper, and we could therefore assume that mortality is not sex-biased during the first summer (Guinness, Albon \& Clutton-Brock 1978). Further, it is unlikely that males have a greater susceptibility of being shot, as licenses for calves are not sex-specific, sexual body-size dimorphism in calves is negligible, and the overall calf sex ratio in harvest data matched exactly the overall foetal sex ratio (Post et al. 1999a). However, inter-annual changes in red deer abundance are not necessarily directly reflected in harvest data. In harvested populations, there is usually a time lag between increased or decreased density and increased or decreased harvest quotas (Fryxell, Mercer \& Gellately 1988; Fryxell et al. 1991; Solberg et al. 1999). Thus, changes in harvest figures from one year to the next may imply both increased harvest quotas and/or increased population size (Solberg et al. 1999). However, over a time span of 5-10years, increased harvest certainly reflects increased population size. We therefore use the absolute harvest number when calculating an index for density, and not the year-to-year changes in abundance used when detrending these time series (Post \& Stenseth 1999). 
Red deer sex ratio and spatial

scale

C 2000 British

Ecological Society

Journal of Animal

Ecology, 69,

959-974

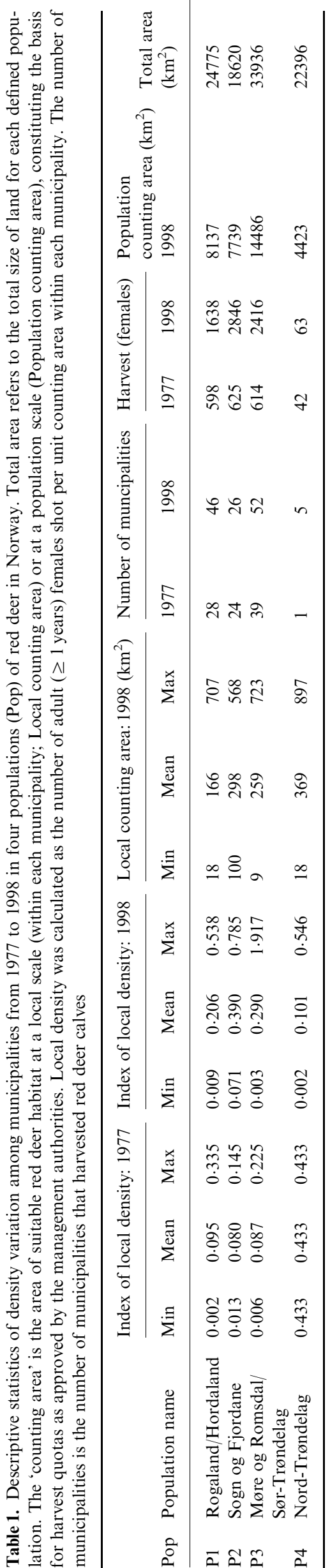

THE NORTH ATLANTIC OSCILLATION

In northern regions on both sides of the Atlantic Ocean, a significant proportion of inter-annual variability in winter precipitation and temperatures is attributable to the dynamics of an atmospheric phenomenon called the North Atlantic Oscillation (NAO; Hurrell 1995). The NAO is a large-scale alternation in atmospheric pressures across the North Atlantic Ocean (Van Loon \& Rogers 1978; Lamb \& Peppler 1987), and its fluctuations and decadal phases are strongly linked to inter-annual variation as well as long-term changes in temperatures and precipitation in the Northern Hemisphere (Hurrell \& Van Loon 1997). The NAO index quantifies the average deviation from the long-term mean sealevel surface pressure difference between Lisbon, Portugal, and Stykkisholmur, Iceland (Hurrell \& Van Loon 1997), for the months of December through March. The NAO index may therefore be an index for winter climate. The index can be found at the Climate Indices website: http:/http:// www.cdg.ucar.edu:80/cas/climind. For a further ecologically focused description of this index, see Post, Forchhammer \& Stenseth (1999b).

For northern ungulates, severe winters are those with deep snow and low temperatures, which impose extreme energetic costs for foraging, locomotion and thermogenesis (Simpson et al. 1978; Parker, Robbins \& Hanley 1984; Hobbs 1989). On the west coast of Norway, the NAO is positively correlated with temperature and precipitation. However, since temperatures in this region are often around $0{ }^{\circ} \mathrm{C}$ during winter, the relationship between the NAO and snow depth may be difficult to predict. Post et al. (1999a) found a positive correlation between snow depth and the NAO at two out of four meteorological stations in Hordaland, and thus argued that a high NAO index indicates severe winter conditions. The best correlation between the NAO and winter snow depth was found for Vintertun (Geographic location no. 47750), a station located $395 \mathrm{~m}$ above sea level (The Norwegian Meteorological Institute, Oslo). Altitude is a strong determining factor for whether precipitation falls as snow or rain. Since red deer mostly stay at low elevation during winter (Albon \& Langvatn 1992), this may not be a representative test of whether there is a correlation between winter severity (snow depth) and the NAO for wintering red deer on the west coast of Norway. In this study we therefore use data on snow depth for 123 meteorological stations along the west coast of Norway (Fig. 1).

\section{STATISTICAL ANALYSES}

To test for a possible non-linear relationships between the response variables (snow depth and proportion of male calves shot in the subsequent 
et al.

(C) 2000 British Ecological Society Journal of Animal Ecology, 69, 959-974 autumn) and the predictor variables, we fitted generalized additive models (GAM) using smoothing splines (Hastie \& Tibshirani 1990; Venables \& Ripley 1994; for application of GAM in ecology, see Yee \& Mitchell 1991; Lambin et al. 1998; Wiser, Peet \& White 1998; Bjørnstad et al. 1999). Splines are piecewise polynomials that are smooth (twice differentiable) in the spline knots (the control points of the splines) (Bjørnstad et al. 1999). The complexity of the curve, i.e. the number of degrees of freedom (d.f.spline), associated with the smoothing spline was selected by repeated fitting of the GAM. We fitted the model with varying d.f.spline for one variable (1-6), while holding d.f.spline of the other variables constant. We then tested the fit of the different models in an ANOVA setting (see Venables \& Ripley 1994: pp. 251-252). In no population was there evidence of any non-linearity between response and predictor variables (all $P>0 \cdot 10$ ). Since we found only linear effects, we only present results from parametric models, as these are more desirable if they fit the data adequately (Yee \& Mitchell 1991).

We evaluated how snow depth was predicted by the NAO, altitude, degree of latitude and degree of longitude with multiple regression. The average length of the 123 time series was 25 years (range 1028). The need for transformation of snow depth was assessed using the Box-Cox transformation family, the parameters being estimated using profile loglikelihood (see Venables \& Ripley 1994). We therefore transformed snow depth as 'log (snow depth $+4)^{\prime}$. We explored potential interactions between the continuous predictor variables by considering products. The predictor variables were standardized (mean 0 , variance 1) to facilitate the interpretation of the interaction terms (Portier et al. 1998). The NAO index is already standardized (it is defined as a normalized pressure difference; Hurrell 1995). When variables are standardized, the coefficient for a variable is the strength of this variable when the other variables are average (because the interaction term is then 0). Separate models were run for December, January, February and March. All models were checked for assumptions of linearity, homoscedasticity, and statistically defined influence values (Cook's D; Venables \& Ripley 1994).

We used parametric logistic regression to determine the relationship between the proportion of males shot (each year in each municipality) and the variables female density index (log transformed), the NAO in the year of gestation (same year as calves are shot), the NAO the year prior to harvest (and conception), degree of latitude and distance from the coast. The last two variables were included since it has been demonstrated that body weight increases with latitude and distance from the coast (Langvatn \& Albon 1986), and we also used the local (municipality) scale for these variables. We also ran separate models adding a population-specific average of snow depth in March (from stations below $125 \mathrm{~m}$ a.s.l. only) before entering the NAO. The number of male calves shot in a particular year and municipality $\left(S_{i}, i=1,2, \ldots, N\right)$ can be assumed to follow a binomial distribution $\operatorname{Bin}\left(S_{i}, \mathrm{p}_{(S i)}\right)$ under the assumption of independence of $S_{i}$, where $\mathrm{p}_{(S i)}$ is the proportion of males shot in a particular municipality and year (Hosmer \& Lemeshow 1989). Any violation of the assumption of independence will lead to unaccounted heterogeneity (overdispersion), and this was assessed by the statistical significance of the Pearson residual $\chi^{2}$ of the fitted model (McCullagh \& Nelder 1989; Tjur 1998). We also used generalized linear mixed models (GLMM; see Lindsey 1999; Milner et al. 1999) to assess if residual heterogeneity between municipalities and years could affect the parameter estimates and their standard errors. Municipalities and years were taken as random effects in the GLMMs, whereas the other factors were kept as fixed factors. We used the statistical package S-Plus when conducting GAM and GLM (Venables \& Ripley 1994), whereas GLMM were implemented in the R package (e.g. Lindsey 1999).

\section{Results}

\section{THE NAO AS A MEASURE OF WINTER SEVERITY}

The correlation between the snow depth and the NAO (Table 2; Jan: $R^{2}=0.370, t=-9.616, P<$ 0.001; Feb: $R^{2}=0.411, \quad t=-12.432, \quad P<0.001$; Mar: $R^{2}=0.502, t=-9.518, P<0.001$; Dec: $R^{2}=$ $0.412, t=0.215, P=0.830)$ along the west coast of Norway from Rogaland to Nord-Trøndelag was dependent on the altitude considered in January, February and March, but not in December when there was no main effect of the NAO (altitude*NAO; Jan: $t=3 \cdot 300, P=0.001$; Feb: $t=3 \cdot 337, P<$ 0.001; Mar: $t=3.424, P=0.001$; Dec: $R^{2}=0.412, t$ $=-0.680, P=0.497)$. There was negative correlation between the NAO and snow depth at low altitude, whereas above approximately $400 \mathrm{~m}$ a.s.1., the correlation was positive (Fig. 2). There was an interaction between the NAO and degree of longitude in January and February only (Jan: $t=2 \cdot 106, P=$ 0.035; Feb: $t=2.958, P=0.003$; Mar: $t=1.446, P=$ 0.148 ; Dec: $t=0.269, P=0.788$ ), i.e. the effect of the NAO on snow depth decreased with longitude, but this disappeared for January when only including significant factors $(t=1.664, \quad P=0.096)$. As expected, snow depth increased with altitude (Jan: $t$ $=15.187, \quad P<0.001$; Feb: $t=16.576, \quad P<0.001$; Mar: $t=19.999, P<0.001$; Dec: $t=18.823, P<$ 0.001). However, snow depth increased faster with altitude at the coast than in the inland (longitude*altitude; Jan: $t=-8.426, P<0.001$; Feb: $t=-$ 9.859, $P<0.001$; Mar: $t=-12.114, P<0.001$; Dec: $t=-8.307, P<0.001$ ), and this effect was in turn 
964

Red deer sex ratio and spatial scale

C) 2000 British Ecological Society Journal of Animal Ecology, 69, 959-974

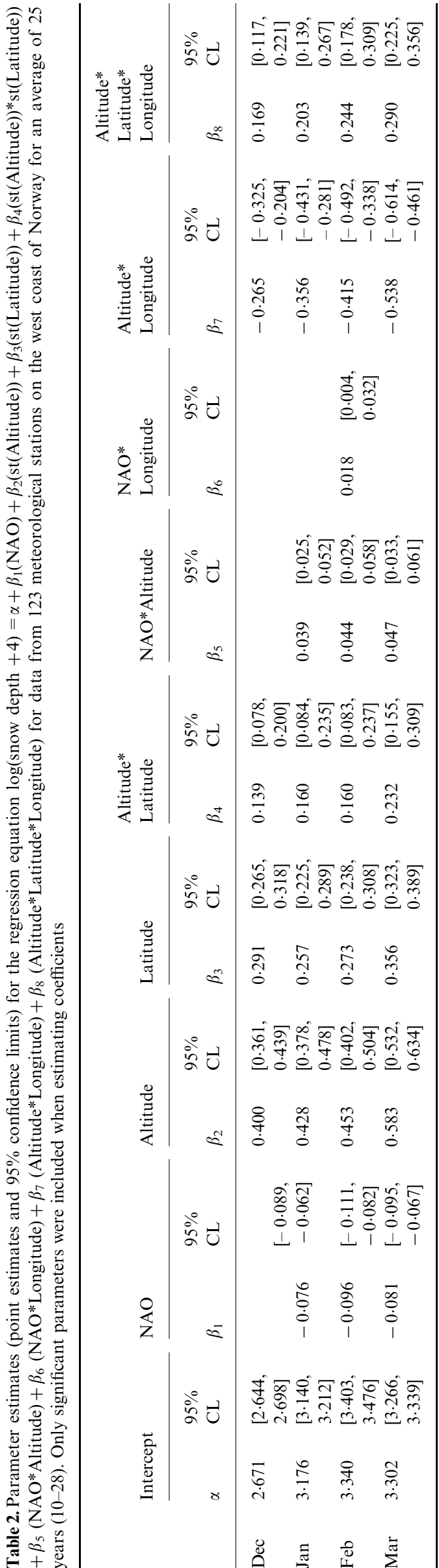

Fig. 2. The correlation between the North Atlantic Oscillation and snow depth in March as a function of altitude in Norway. Each datapoint is a correlation coefficient between the NAO and snow depth for a specific meteorological station. Note that analysis was done directly on snow depth, and that several other factors also affected snow depth (see Table 2).

stronger in the south than in the north (altitude*latitude*longitude; Jan: $t=5.529, P<0.001$; Feb: $t=$ 7.089, $P<0.001$; Mar: $t=7.368, P<0.001$; Dec: $t$ $=6.159, P<0.001)$. There was also an interaction between altitude and degree of latitude (Jan: $t=$ 3.558, $P<0.001$; Feb: $t=3.687, P<0.001$; Mar: $t$ $=4.981, P<0.001$; Dec: $t=4.358, P<0.001$ ), i.e. precipitation tends to fall as snow at lower altitudes further north, probably as an effect of declining temperatures with latitude. There was a main (positive) effect of degree of latitude (Jan: $t=9.784, P<$ 0.001; Feb: $t=10.433, P<0.001$; Mar: $t=11.893$, $P<0.001$; Dec: $t=13.672, \quad P<0.001)$, whereas there was no main effect of degree of longitude (Jan: $t=-1.333, P=0.183$; Feb: $t=-1.329, P=0.184$; Mar: $t=0.102, \quad P=0.919$; Dec: $t=-1.200, \quad P=$ 0.230 ). The other interactions were not significant (NAO*altitude*latitude; Jan: $t=1.220, \quad P=0.223$; Feb: $t=1.001, P=0.317$; Mar: $t=1.026, P=0.305$; Dec: $t=0.136, P=0.892$; NAO*longitude*altitude; Jan: $t=-0.770, P=0.442$; Feb: $t=-1.256, P=$ 0.209; Mar: $t=-1.670, P=0.095$; Dec: $t=0.079, P$ $=0.937 ; \mathrm{NAO}^{*}$ longitude*altitude*latitude; Jan: $t=$ $-0.159, P=0.874$; Feb: $t=0.940, P=0.347$; Mar: $t$ $=1.137, P=0.256$; Dec: $t=-0.592, P=0.554)$.

\section{SEX RATIOS IN RED DEER}

In all four populations, the proportion of male calves shot each autumn declined markedly as density increased (Fig. 3; Table 3; P1: d.f. $=1, \chi^{2}=$ 11.604, $P<0.001 ;$ P2: d.f. $=1, \quad \chi^{2}=58.823, P<$ 0.001; P3: d.f. $=1, \chi^{2}=23.344, P<0.001$; P4: d.f. $=$ $\left.1, \chi^{2}=4.085, P=0.043\right)$. This includes the popula- 

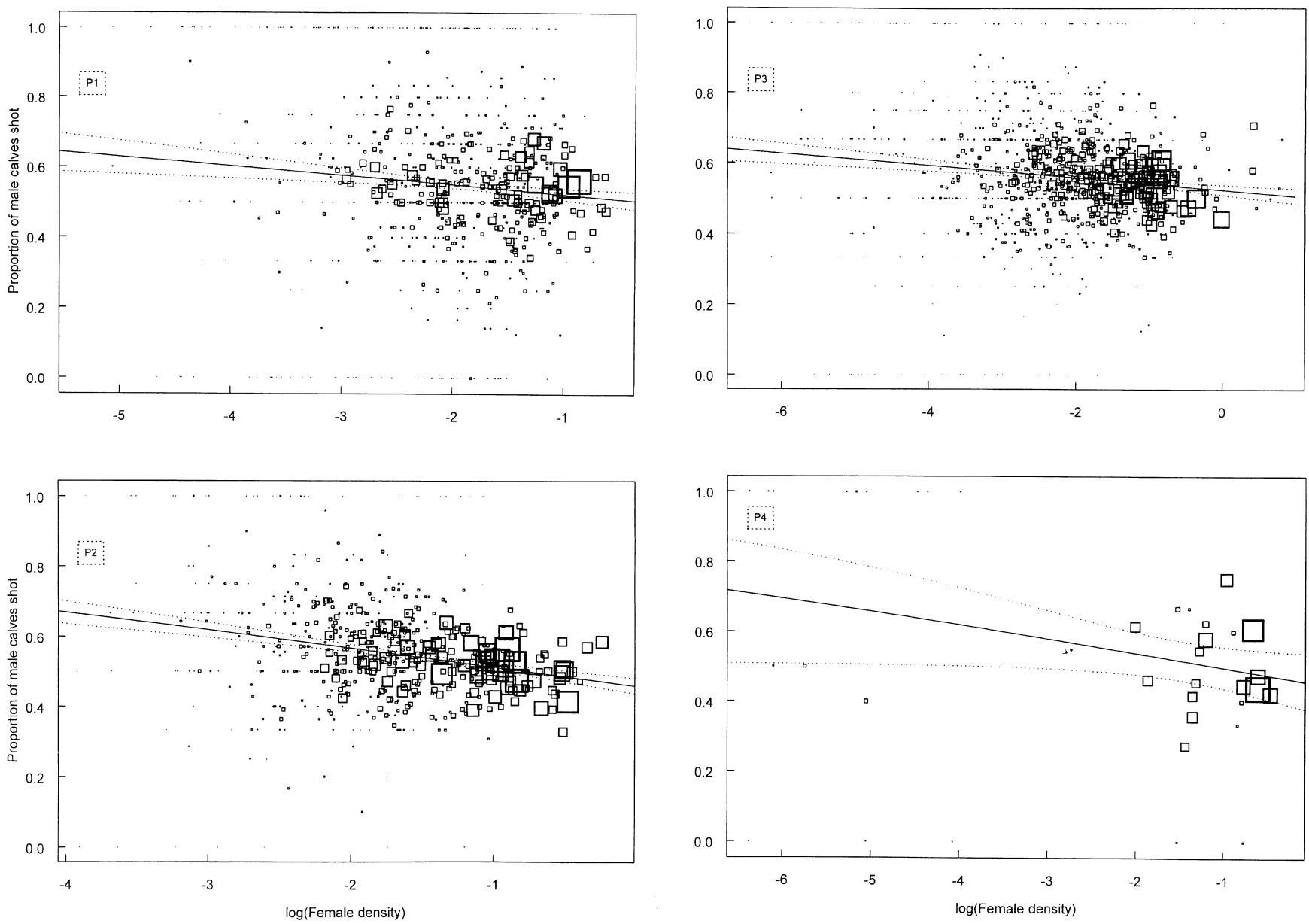

Fig. 3. Proportion of male calves shot each autumn as a function of density in four populations of Norwegian red deer; (a) P1; (b) P2; (c) P3; (d) P4. Each square represents data from one municipality one year. The size of the square is directly proportional to the sample size.

(C) 2000 British Ecological Society Journal of Animal Ecology, 69, 959-974 tion (P1) used in Post et al. (1999a). The effect of density, as estimated from the regression coefficient, was stronger in P2 compared to P1 and P3 (Table $3)$. This comparison was justified as we use $\log$ (density), and the regression coefficient therefore represents the impact of a relative increase in density, not an absolute one (i.e. they represent the impact of the same relative increase in density). Our analysis confirmed that the proportion of male calves shot each autumn increased with increasing NAO in P1 independent of density (Fig. $4 ; \chi^{2}=5.234, P=0.022$ ), but there was no evidence for an effect of the NAO on offspring sex ratios in the other populations $(\mathrm{P} 2$ : $\chi^{2}=0.136, P=0.712 ; \mathrm{P} 3: \chi^{2}=2.503, P=0.114 ; \mathrm{P} 4$ $\left.\chi^{2}=0.185, P=0.667\right)$. There was no effect of the NAO one year before gestation $\left(\mathrm{P} 1: \chi^{2}=0.011, P=\right.$ 0.916; P2: $\chi^{2}=0.521, P=0.471$; P3: $\chi^{2}=1.311, P=$ 0.252; P4: $\chi^{2}=3.226, P=0.080$ ). In the model with snow depth entered before the NAO, there was clear evidence that the proportion of male calves shot each autumn decreased with increasing snow depth in March, but this was significant only in P1 (P1: $\chi^{2}$
=4.129, $P=0.042 ; \mathrm{P} 2: \chi^{2}=2.005, P=0.157 ; \mathrm{P} 3: \chi^{2}$ $=0.634, P=0.426$; P4: $\left.\chi^{2}<0.001, P=0.979\right)$. There was no residual effect of the NAO after snow depth was accounted for (P1: $\left.\chi^{2}=2.449, P=0.118\right)$. The proportion of male calves shot each autumn further declined with degree of latitude in P1 only (P1: $\chi^{2}=$ 9.228, $P=0.002$; P2: $\chi^{2}=0.064, P=0.800$; P3: $\chi^{2}=$ 0.537, $P=0.464$; P4: $\left.\chi^{2}=0.880, P=0.348\right)$. In $\mathrm{P} 2$, the proportion of male calves shot each autumn increased with increasing distance from the coast $\left(\chi^{2}=7.556 ; P=0.006\right)$, but not in the other populations $\left(\mathrm{P} 1: \chi^{2}=0.066, P=0.798 ; \mathrm{P} 3: \chi^{2}=2.477, P=\right.$ 0.116; P4: $\left.\chi^{2}=0.047, P=0.829\right)$. There was no evidence of overdispersion in the models when including only significant factors (P1: d.f. $=793, \chi^{2}=$ 794.597, $P=0.477$; P2: d.f. $=564, \chi^{2}=558.358, P=$ 0.559; P3: d.f. $=1018, \chi^{2}=971.859, P=0.847$; P4: d.f. $\left.=42, \chi^{2}=34.087, P=0.802\right)$. This indicates that the amount of residual heterogeneity between municipalities and years was small, and that including years and municipalities as random factors would not affect the results significantly. Indeed, regression 
Red deer sex ratio and spatial scale

C 2000 British Ecological Society Journal of Animal Ecology, 69, 959-974

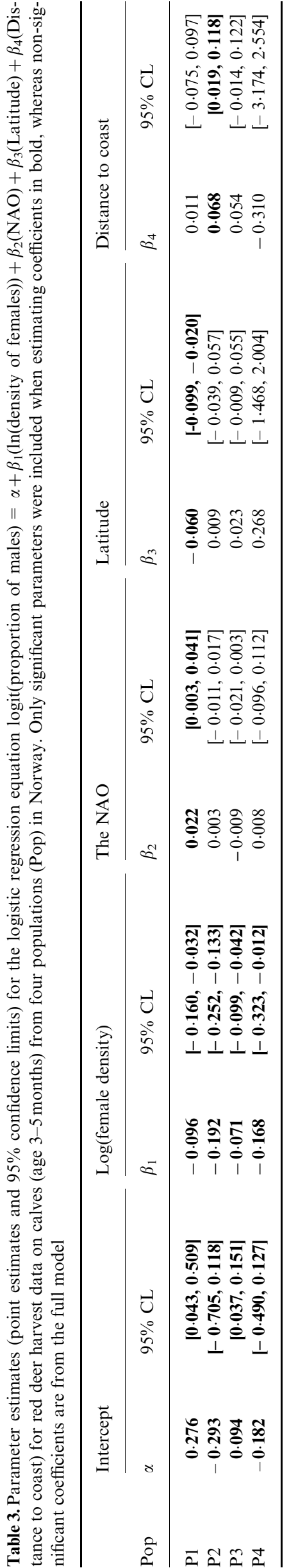

coefficients and their standard errors were very similar (e.g. for population P1, the regression coefficient for density was estimated to be $-0.101, \mathrm{SE}=0.035$ when including municipality as a random factor, and $-0.092, \mathrm{SE}=0.035$ when including year as a random factor; the GLM estimate was -0.092, SE $=0.035$; all models including NAO, degree of latitude and distance from the coast as covariates). The estimates of the random factor standard deviation were always small (e.g. for population P1: municipalities: 0.048, $\mathrm{SE}=0.021$; years: 0.0009, $\mathrm{SE}=0.021$ ).

\section{Discussion}

Recent studies have demonstrated that extrinsic factors affecting body condition of ungulates, such as density and climate, may also affect offspring sex ratios (Kruuk et al. 1999; Post et al. 1999a). The surprising result of Post et al. (1999a), that female red deer in Norway produced increasingly malebiased offspring sex ratios as density increased, was not supported by our analysis of an expanded data set and with a higher spatial resolution, taking into account local density reflecting population heterogeneity. Sex ratios among calves shot in autumn became less male-biased as density increased in all four populations of Norwegian red deer, as earlier reported by Kruuk et al. (1999) for red deer on Rum, Scotland. Our contrasting result was not due to any mistakes in the analysis performed by Post et al. (1999a); their conclusion was right at the coarse (population) scale. Rather, during the time span of their study (1977-93), the number of municipalities harvesting red deer calves increased from 28 to 40 in P1 (referred to in Post et al. (1999a) as the Hordaland population). The decreasing proportion of male calves harvested with increasing local density within the original 28 municipalities was counteracted at the coarse (population) scale by an increased number of male calves harvested in the 12 new municipalities (range expansion) with a low population density. Surprisingly therefore local (municipality) and coarse (population) scale sex ratio were negatively correlated for this period in $\mathrm{P} 1$. The strong effect of local density on population sex ratio was parallelled by decreased adult body weights (A. Mysterud, N.G. Yoccoz, N.C. Stenseth \& R. Langvatn, unpublished results). Body weight of Norwegian red deer also decreases with increasing distance from the coast (Langvatn \& Albon 1986), but distance from the coast was a poor predictor of sex ratio variation, as it only affected the proportion of males born in Sogn og Fjordane (P2).

An increase in the NAO resulted in increasingly male-biased sex ratios in $\mathrm{P} 1$, as previously reported by Post et al. (1999a), but not in the other three populations. Post et al. (1999a) suggested that the NAO index was positively correlated with snow depth and thus high index values indicated severe 
967

A. Mysterud

et al.

(C) 2000 British

Ecological Society

Journal of Animal

Ecology, 69,

959-974

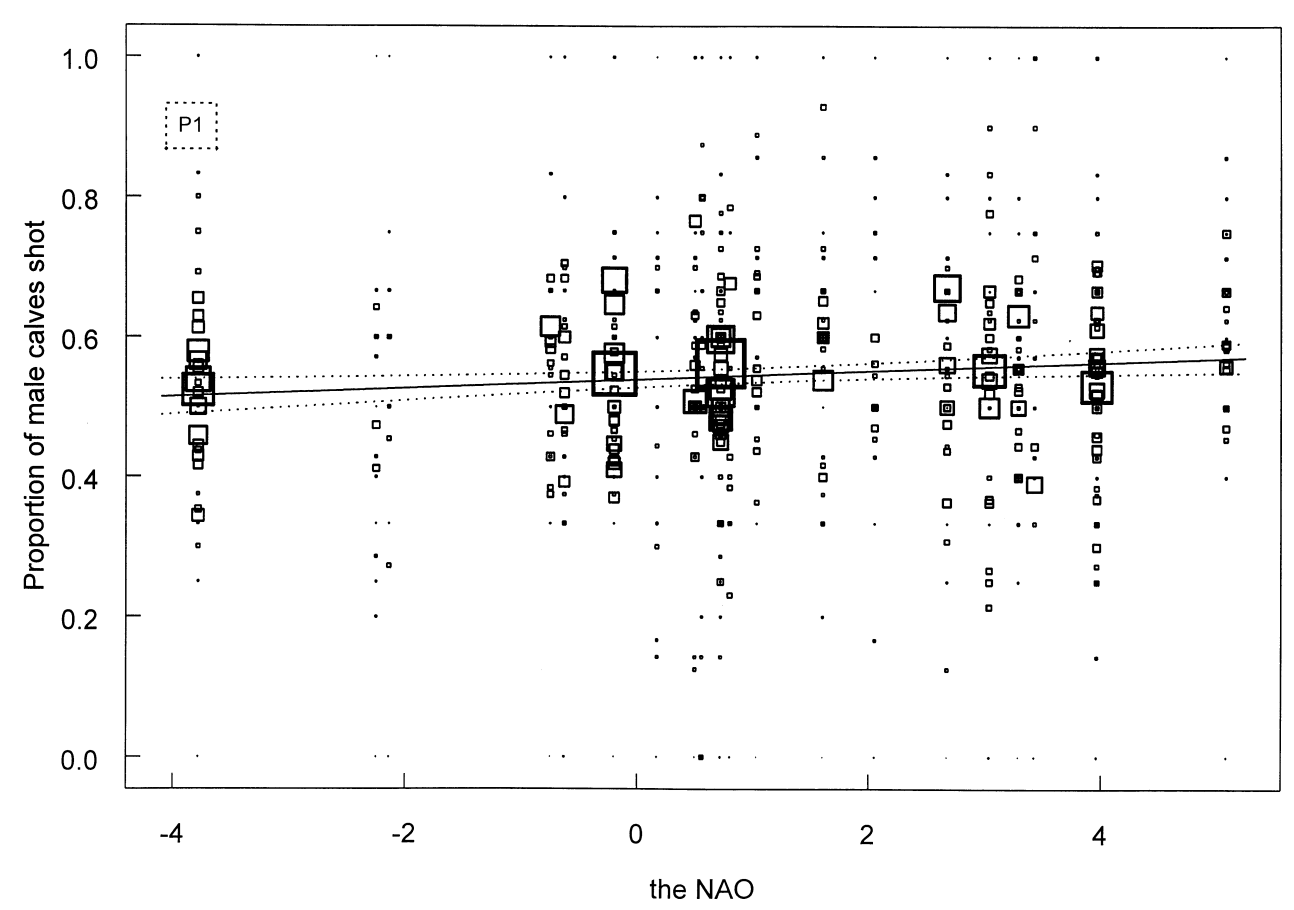

Fig. 4. Proportion of male calves shot each autumn as a function of climate (NAO) in Rogaland and Hordaland (P1) in Norway. Each square represents data from one municipality one year. The size of the square is directly proportional to the sample size.

winters for red deer. In addition, Post et al. (1997) and Post \& Stenseth (1999) reported that body weights of Norwegian red deer were negatively correlated with the NAO. That females in poor condition (i.e. high NAO index) produce more sons (Post et al. 1999a) may thus seem inconsistent with Kruuk et al. (1999), who reported that the proportion of red deer males born on Rum each year declined with winter rainfall which was associated with nutritional stress during pregnancy. However, we challenge the view that high $\mathrm{NAO}$ values indicate severe winters for red deer in Norway, as both the reported positive correlation between the NAO and snow depth (Post et al. 1999a) and the negative correlation between the NAO and red deer body weight (Post et al. 1997; Post \& Stenseth 1999) were not supported. First, red deer in Norway winter at low elevations (Albon \& Langvatn 1992). Although a high NAO index was indicative of higher precipitation, the warmer temperatures at higher NAO (Hurrell 1995; Post et al. 1997) result in a negative correlation between snow depth and the NAO at low elevation (Fig. 2). Forage in the field layer is thus probably more easily available to red deer in these coastal and lowland areas during winters with a high NAO index (Loison, Langvatn \& Solberg 1999b), and the higher temperatures also represent less cold stress to the animals (Simpson et al. 1978). Loison et al. (1999b) reported that body weight of Norwegian red deer in their study population
(Snillfjord in Sør-Trøndelag) was positively correlated with the NAO. Recently, we have found that body weights of red deer in Norway in general were positively correlated with the NAO when taking population substructure into account and using an index for local density, although this relationship was reversed at very low NAO values (A. Mysterud, N.G. Yoccoz, N.C. Stenseth \& R. Langvatn, unpublished results). Further work is needed to determine how the NAO describes local weather at different altitudes and latitudes in different geographical regions before any firm conclusion can be drawn regarding global climate effects on demography and population dynamics of northern ungulates in general (e.g. Post et al. 1997, 1999a,b; Forchhammer et al. 1998; Post \& Stenseth 1998, 1999).

The evolutionary origin of sex ratio variation in relation to body condition may be adaptive and apply on a relative basis between individuals (Trivers \& Willard 1973). However, the extrinsic modification of ungulate sex ratios by population density and climate occurs at a population scale and may not be adaptive (Kruuk et al. 1999; Post et al. 1999a). The physiological mechanism by which sex ratio is determined in red deer remains unknown, which indeed has been a major problem with studies of sex ratio variation in large herbivores in general (Hewison \& Gaillard 1999). Possible mechanisms include a higher in utero mortality of males under harsh conditions, and modification of the sex ratio 
Red deer sex ratio and spatial scale

(C) 2000 British Ecological Society Journal of Animal Ecology, 69, 959-974 at conception and/or implantation. The effect of density on harvest sex ratio can be through both these mechanisms, and our reanalyses revealed that the NAO was a less important predictor of sex ratio than population density also in P1, as measured by the regression coefficients (Table 3 ). The proportion of stillbirths in the polytocous roe deer (Capreolus capreolus L.) increased with increasing density (Andersen \& Linnell 1998). The magnitude of foetal mortality among prime age female red deer is probably low because the proportion of prime age females that ovulated approached $100 \%$ by 15 November in Norwegian red deer, and because close to $100 \%$ of these females showed signs of parturition and were lactating when shot during the following autumn (Langvatn et al. 1996). However, we cannot rule out foetal mortality as a mechanism among yearling and primiparous hinds, which also have a more variable ovulation rate (Langvatn et al. 1996). Indeed, it is difficult to explain the effect of the NAO in population $\mathrm{Pl}$ otherwise, since the NAO is measured from December through March (Hurrell 1995), i.e. during gestation. It is assumed that also body condition at the time of conception affects the sex ratio (Trivers \& Willard 1973; Hewison \& Gaillard 1999). Consequently, sex ratio variation may be dependent on summer food resources and involving both density-dependent and densityindependent mechanisms. Furthermore, it is well documented that the period from spring through early autumn is the prime period for growth and build-up of body condition, a natural consequence both from a resource perspective (Wood, Cowan \& Nordan 1962; Klein 1964; Anderson, Medin \& Bowden 1974; Mitchell, McCowan \& Nicholson 1976; Langvatn 1994), and in terms of physiological (Moen 1978; Kay 1985; Parker et al. 1993) and hormonal status of animals (Bahnak et al. 1981; Ryg \& Langvatn 1982; Ryg 1982). Although the NAO is an index of severity of winter climate, it may also be correlated with summer foraging conditions because increased snow depth may lead to a prolonged period of snow melt and hence access to newly emergent and high quality forage (Albon \& Langvatn 1992; Langvatn 1994; Post \& Stenseth 1999). However, the NAO of the year prior to gestation did not affect sex ratios, and hence there was no evidence of any indirect effect of the NAO on the summer ranges that could influence condition of individual red deer hinds sufficiently at time of conception to affect harvest sex ratios the next autumn.

On the basis of this study, our conclusions are as follows.

1. There is evidence that with increasing density and severity of winter climate (low NAO), females may produce decreasingly male-biased offspring sex ratios. There was thus support for the extrinsic modification hypothesis (Kruuk et al. 1999; Post et al. 1999a).
2. There was no evidence that abiotic factors can be more influential than density-dependent resource limitation in altering sex ratios (Post et al. 1999a), as density was about twice as important as winter climate measured with the NAO index.

3. These patterns imply that there is, at present, no empirical evidence for the hypothesis that females in poor condition produce more sons as poor sons may nevertheless survive better than poor daughters (Post et al. 1999a), or that the contradiction may be explained by considering interactions between the timing of sex-specific foetal growth spurts and environmental stress on maternal condition (Forchhammer 2000).

\section{Acknowledgements}

We thank Steve Albon, Jean-Michel Gaillard, Mark Hewison, Rolf A. Ims, Loeske Kruuk and Anne Loison for valuable comments to previous drafts. We gratefully acknowledge the financial support of the National Science Council to A.M. (Project no. 129208/720). We thank Eric Post for very useful discussions regarding red deer and the NAO, and Bernd Etzelmüller, Kristian Kihle and Hans Chr. Udnæs for help with various aspects in making Fig. 1 .

\section{References}

Albon, S.D. \& Langvatn, R. (1992) Plant phenology and the benefits of migration in a temperate ungulate. Oikos, 65, 502-513.

Andersen, R. \& Linnell, J.D.C. (1998) Ecological correlates of mortality of roe deer fawns in a predator-free environment. Canadian Journal of Zoology, 76, 1217-1225.

Anderson, A.E., Medin, D.E. \& Bowden, D.C. (1974) Growth and morphometry of the carcass, selected bones, organs, and glands of mule deer. Wildlife Monographs, 39, 1-122.

Bahnak, B.R., Holland, J.C., Verme, L.J. \& Ozoga, J.J. (1981) Seasonal and nutritional influences on growth hormone and thyroid activity in white-tailed deer. Journal of Wildlife Management, 45, 140-147.

Bjørnstad, O.N., Fromentin, J.-M., Stenseth, N.C. \& Gjøsæter, J. (1999) A new test for density-dependent survival: the case of the coastal cod populations. Ecology, 80, 1278-1288.

Cameron, E.Z., Linklater, W.L., Stafford, K.J. \& Veltman, C.J. (1999) Birth sex ratios relate to mare condition at conception in Kaimanawa horses. Behavioral Ecology, 10, 472-475.

Clutton-Brock, T.H. (1991). The Evolution of Parental Care. Princeton University Press Princeton, NJ.

Clutton-Brock, T.H., Guinness, F.E. \& Albon, S.D. (1982). Red Deer. Behaviour and Ecology of Two Sexes. Edinburgh University Press, Edinburgh.

Clutton-Brock, T.H. \& Iason, G.R. (1986) Sex ratio variation in mammals. Quarterly Review of Biology, 61, 339-374.

Coulson, T.N., Albon, S.D., Guinness, F.E., Pemberton, J.M. \& Clutton-Brock, T.H. (1997) Population substructure, local density, and calf winter survival in red deer (Cervus elaphus). Ecology, 78, 852-863. 
A. Mysterud et al.
Coulson, T., Albon, S., Pilkington, J. \& Clutton-Brock, T. (1999) Small-scale spatial dynamics in a fluctuating ungulate population. Journal of Animal Ecology, 68, 658-671.

Donalson, D.D. \& Nisbet, R.M. (1999) Population dynamics and spatial scale: effects of system size on population persistence. Ecology, 80, 2492-2507.

Festa-Bianchet, M. (1996) Offspring sex ratio studies of mammals: does publication depend upon the quality of the research or the direction of the results? Ecoscience, 3, 42-44.

Forchhammer, M.C. (2000) Timing of foetal growth spurts can explain sex ratio variation in polygynous mammals. Ecology Letters, 3, 1-4.

Forchhammer, M.C., Stenseth, N.C., Post, E.S. \& Langvatn, R. (1998) Population dynamics of Norwegian red deer: density-dependence and climatic variation. Proceedings of the Royal Society London Series B, 265, 341-350.

Fryxell, J.M., Hussell, D.J.T., Lambert, A.B. \& Smith, P.C. (1991) Time lags and population fluctuations in white-tailed deer. Journal of Wildife Management, 55, 377-385.

Fryxell, J.M., Mercer, W.E. \& Gellately, R.B. (1988) Population dynamics of Newfoundland moose using cohort analysis. Journal of Wildlife Management, 5, 14-21.

Guinness, F.E., Albon, S.D. \& Clutton-Brock, T.H. (1978) Factors affecting reproduction in red deer (Cervus elaphus) hinds on Rhum. Journal of Reproduction and Fertility, 54, 325-334.

Hastie, T. \& Tibshirani, R. (1990) Generalised Additive Models. Chapman \& Hall, London.

Hewison, A.J.M., Andersen, R., Gaillard, J.-M., Linnell, J.D.C. \& Delorme, D. (1999) Contradictory findings in studies of sex ratio variation in roe deer (Capreolus capreolus). Behavioral Ecology and Sociobiology, 45, 339-348.

Hewison, A.J.M. \& Gaillard, J.-M. (1999) Successful sons or advantaged daughters? The Trivers-Willard model and sex-biased maternal investment in ungulates. Trends in Ecology and Evolution, 14, 229-234.

Hobbs, N.T. (1989) Linking energy balance to survival in mule deer: development and test of a simulation model. Wildlife Monographs, 101, 1-39.

Hosmer, D.W. \& Lemeshow, S. (1989) Applied Logistic Regression. Wiley, New York.

Hurrell, J.W. (1995) Decadal trends in the North Atlantic Oscillation: regional temperatures and precipitation. Science, 269, 676-679.

Hurrell, J.W. \& Van Loon, H. (1997) Decadal variations in climate associated with the North Atlantic Oscillation. Climatic Change, 36, 310-326.

Kay, R.N.B. (1985) Seasonal variation of appetite in ruminants. Recent Advances in Animal Nutrition (ed. W. Haresign), pp. 199-210. Butterworths, London.

Klein, D.R. (1964) Range-related differences in growth of deer reflected in skeletal ratios. Journal of Mammalogy, 45, 226-235.

Kruuk, L.E.B., Clutton-Brock, T.H., Albon, S.D., Pemberton, J.M. \& Guinness, F.E. (1999) Population density affects sex ratio variation in red deer. Nature, 399, 459-461.

Lamb, P.J. \& Peppler, R.A. (1987) North Atlantic Oscillation: concept and an application. American Meteorological Society, 68, 1218-1225.

(C) 2000 British Ecological Society Journal of Animal Ecology, 69, 959-974

Lambin, X., Elston, D.A., Petty, S.J. \& MacKinnon, J.L. (1998) Spatial asynchrony and periodic travelling waves in cyclic populations of field voles. Proceedings of the Royal Society London Series B, 265, 1491-1496.
Langvatn, R. (1994) Climate associated variation in the resource base for red deer (Cervus elaphus) - relationships to body size and reproductive performance within and between cohorts. PhD Thesis, University of Oslo.

Langvatn, R. \& Albon, S.D. (1986) Geographic clines in body weight of Norwegian red deer: a novel explanation of Bergmann's rule? Holarctic Ecology, 9, 285293.

Langvatn, R., Albon, S.D., Burkey, T. \& Clutton-Brock, T.H. (1996) Climate, plant phenology and variation in age at first reproduction in a temperate herbivore. Journal of Animal Ecology, 65, 653-670.

Lindsey, J.K. (1999) Models for Repeated Measurements. Oxford University Press, Oxford.

Loison, A., Gaillard, J.-M., Pelabon, C. \& Yoccoz, N.G. (1999a) What factors shape sexual size dimorphism in ungulates? Evolutionary Ecology Research, 1, 611-633.

Loison, A., Langvatn, R. \& Solberg, E.J. (1999b) Body mass and winter mortality in red deer calves: Disentangling sex and climate effects. Ecography, 22, 20-30.

Maynard Smith, J. (1980) A new theory of sexual investment. Behavioral Ecology and Sociobiology, 7, 247-251.

McCullagh, P. \& Nelder, J.A. (1989) Generalized Linear Models. Chapman \& Hall, London.

Milner, J.M., Elston, D.A. \& Albon, S.D. (1999) Estimating the contributions of population density and climatic fluctuations to interannual variation in survival of Soay sheep. Journal of Animal Ecology, 68, 12351247.

Mitchell, B., McCowan, D. \& Nicholson, I.A. (1976) Annual cycles of body weight and condition in Scottish red deer, Cervus elaphus. Journal of Zoology, 180, 107127.

Moen, A.N. (1978) Seasonal changes in heart rates, activity, metabolism, and forage intake of white-tailed deer. Journal of Wildlife Management, 42, 715-738.

Parker, K.L., Gillingham, M.P., Hanley, T.A. \& Robbins, C.T. (1993) Seasonal patterns in body mass, body composition, and water transfer rates of free-ranging and captive black-tailed deer (Odocoileus hemionus sitkensis). Canadian Journal of Zoology, 71, 1397-1404.

Parker, K.L., Robbins, C.T. \& Hanley, T.A. (1984) Energy expenditure for locomotion by mule deer and elk. Journal of Wildlife Management, 48, 474-488.

Portier, C., Festa-Bianchet, M., Gaillard, J.-M., Jorgenson, J.T. \& Yoccoz, N.G. (1998) Effects of density and weather on survival of bighorn sheep lambs (Ovis canadensis). Journal of Zoology, 245, 271-278.

Post, E., Forchhammer, M.C. \& Stenseth, N.C. (1999b) Population ecology and the North Atlantic Oscillation (NAO). Ecological Bulletins, 47, 117-125.

Post, E., Forchhammer, M.C., Stenseth, N.C. \& Langvatn, R. (1999a) Extrinsic modification of vertebrate sex ratios by climatic change. American Naturalist, 154, 194-204.

Post, E. \& Stenseth, N.C. (1998) Large-scale climatic fluctuations and population dynamics of moose and whitetailed deer. Journal of Animal Ecology, 67, 537-543.

Post, E. \& Stenseth, N.C. (1999) Climatic variability, plant phenology, and northern ungulates. Ecology, 80, 13221339.

Post, E., Stenseth, N.C., Langvatn, R. \& Fromentin, J.-M. (1997) Global climate change and phenotypic variation among red deer cohorts. Proceedings of the Royal Society London Series B, 264, 1317-1324.
Ray, C. \& Hastings, A. (1996) Density dependence: are we searching at the wrong spatial scale? Journal of Animal Ecology, 65, 556-566. 
Red deer sex ratio and spatial scale
Ryg, M. (1982) Seasonal changes in weight gain, growth hormone, and thyroid hormones in intact and castrated male moose (Alces alces alces). Canadian Journal of Zoology, 60, 2941-2946.

Ryg, M. \& Langvatn, R. (1982) Seasonal changes in weight gain, growth hormone, and thyroid hormones in male red deer (Cervus elaphus atlanticus). Canadian Journal of Zoology, 60, 2577-2581.

Simpson, A.M., Webster, A.J.F., Smith, J.S. \& Simpson, C.A. (1978) Energy and nitrogen metabolism of red deer (Cervus elaphus) in cold environments; a comparison with cattle and sheep. Journal of Comparative Biochemistry and Physiology, 60, 251-256.

Skogland, T. (1986) Sex ratio variation in relation to maternal condition and parental investment in wild reindeer Rangifer t. tarandus. Oikos, 46, 417-419.

Smith, B.L. \& Anderson, S.H. (1996) Patterns of neonatal mortality of elk in northwest Wyoming. Canadian Journal of Zoology, 74, 1229-1237.

Solberg, E.J., Sæther, B.-E., Strand, O. \& Loison, A. (1999) Dynamics of a harvested moose population in a variable environment. Journal of Animal Ecology, 68, 186-204.

Statistics Norway (1977-98) Official Hunting Statistics of Norway. Statistics Norway, Oslo and Kongsvinger.

Tjur, T. (1998) Nonlinear regression, quasi likelihood, and overdispersion in generalized linear models. American Statistician, 52, 222-227.
Trivers, R.L. \& Willard, D.E. (1973) Natural selection of parental ability to vary the sex ratio of offspring. Science, 179, 90-92.

Van Loon, H. \& Rogers, J.C. (1978) The seesaw in winter temperatures between Greenland and northern Europe. I. General description. Montly Weather Review, 106, 296-310.

Venables, W.N. \& Ripley, B.D. (1994) Modern Applied Statistics with S-Plus. Springer Verlag, New York.

Weckerly, F.W. (1998) Sexual-size dimorphism: influence of mass and mating system in the most dimorphic mammals. Journal of Mammalogy, 79, 33-52.

Williams, G.C. (1979) The question of adaptive sex ratio in outcrossed vertebrates. Proceedings of the Royal Society London Series B, 205, 567-580.

Wiser, S.K., Peet, R.K. \& White, P.S. (1998) Prediction of rare-plant occurrence: a southern Appalachian example. Ecological Applications, 8, 909-920.

Wood, A.J., McT., Cowan, I. \& Nordan, H.C. (1962) Periodicity of growth in ungulates as shown by deer of the genus Odocoileus. Canadian Journal of Zoology, 40, 593-603.

Yee, T.W. \& Mitchell, N.D. (1991) Generalized additive models in plant ecology. Journal of Vegetation Science, 2, 587-602.

Received 8 February 2000; revision received 3 June 2000
(C) 2000 British

Ecological Society Journal of Animal Ecology, 69, 959-974 


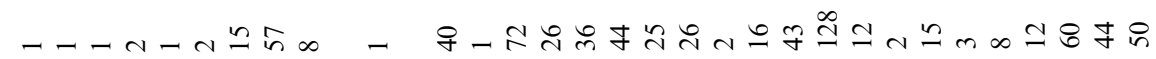
- n-

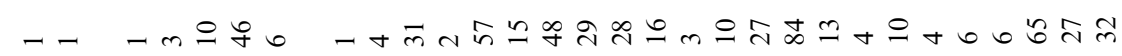

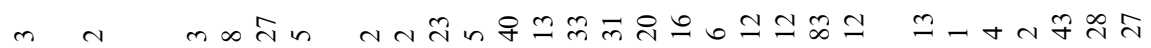

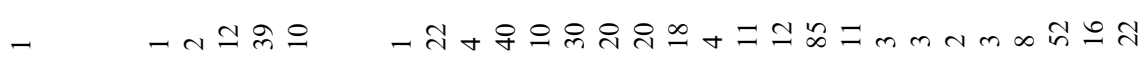

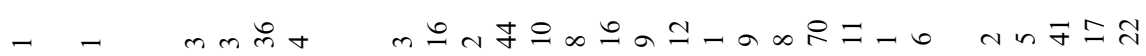

ลิ- -ナกสิ๓-

- - +

- n= $\quad$ -

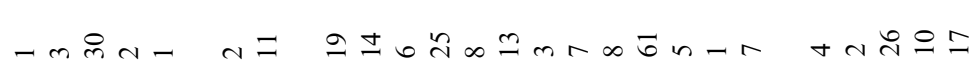
-m ニ-

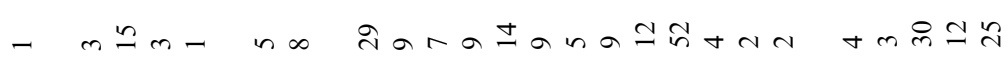

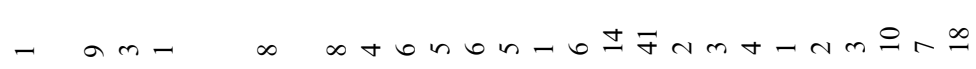

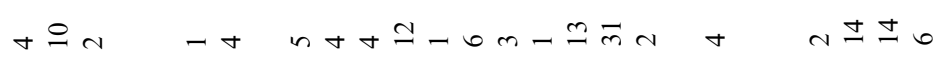
- I -0 = -ma-n ominombontan nab

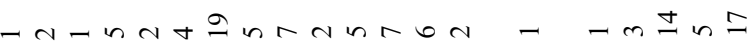

$$
\begin{aligned}
& \text { i tat-a-tha in } 0 \text { in } 0 \\
& \text { o-mman - - }
\end{aligned}
$$

$\stackrel{8}{2}$

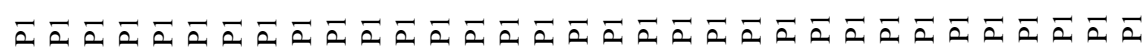


972

Red deer sex ratio and spatial scale

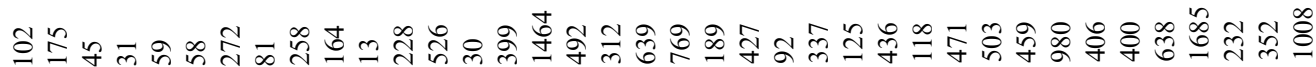

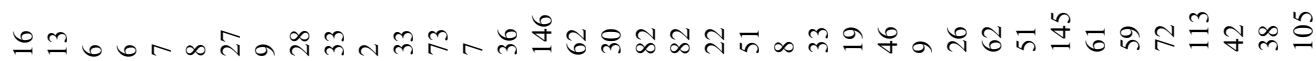

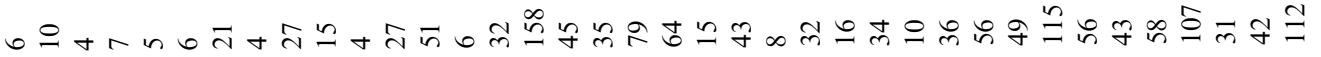

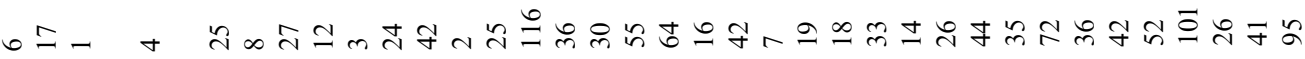

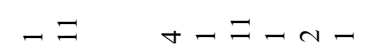

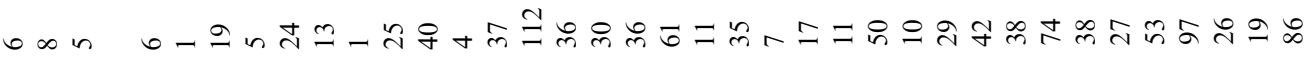

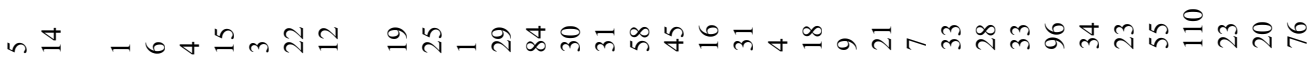

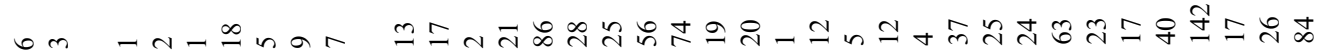

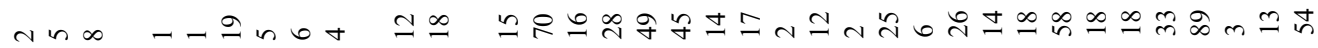

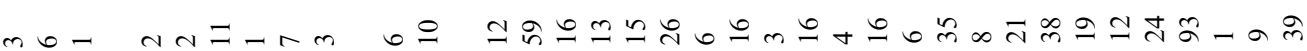
minm nammo

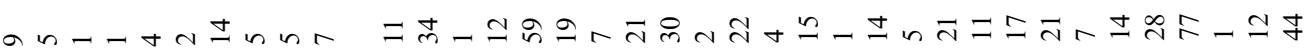
nom n

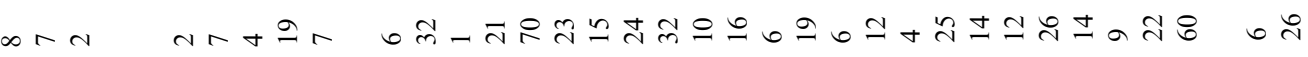

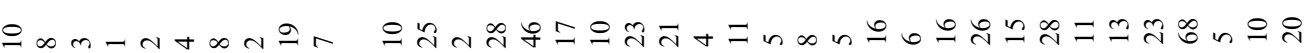

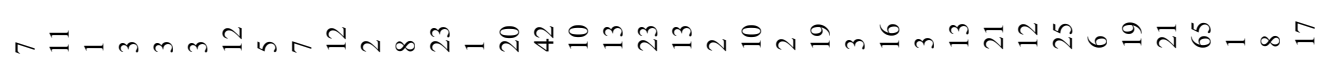

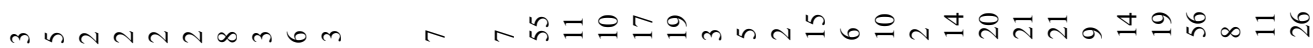

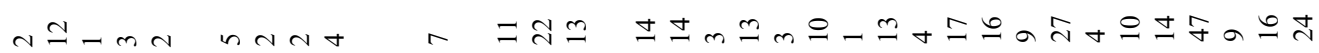

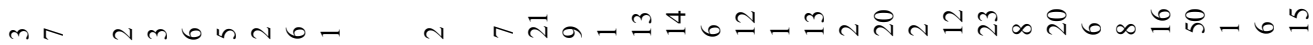
nnh-totm

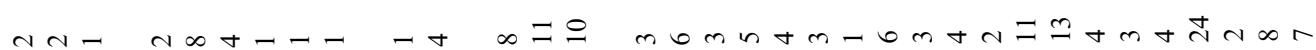

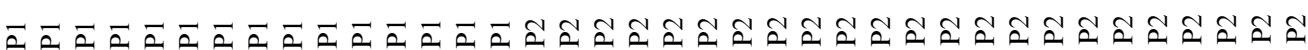

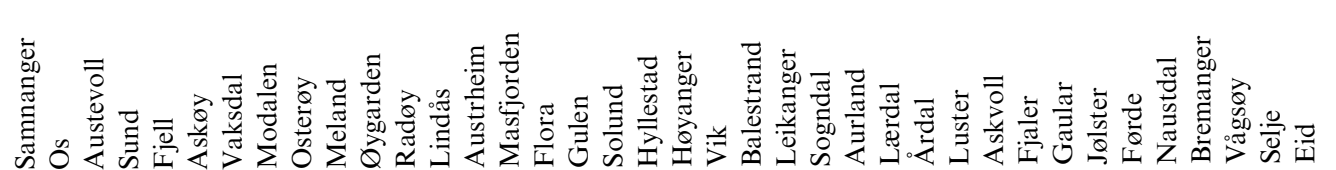


973

A. Mysterud

et al.
(C) 2000 British Ecological Society Journal of Animal Ecology, 69, 959-974

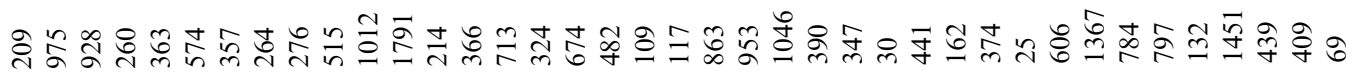

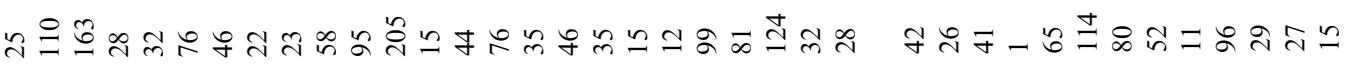

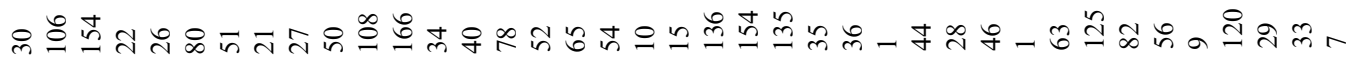

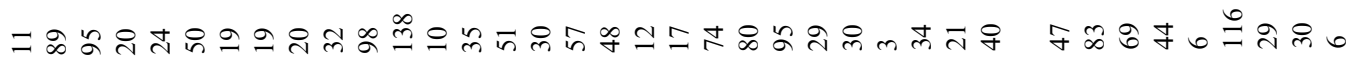

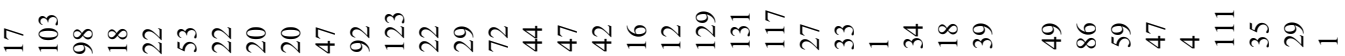

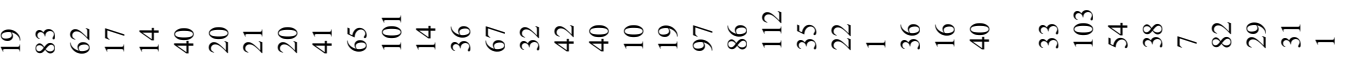

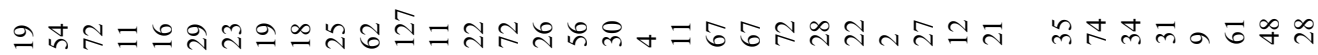

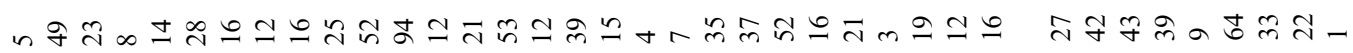

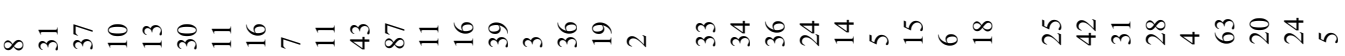

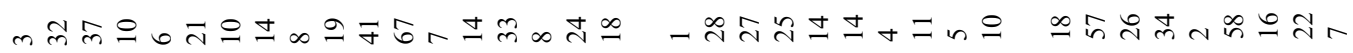

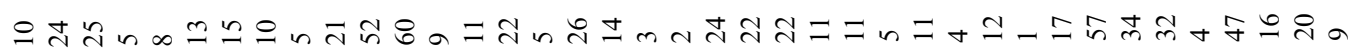

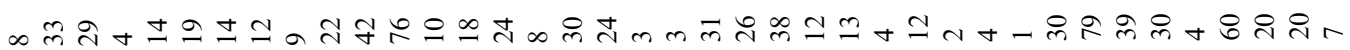

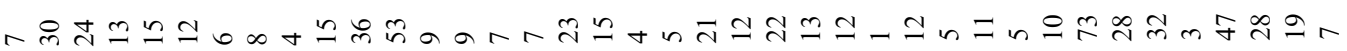

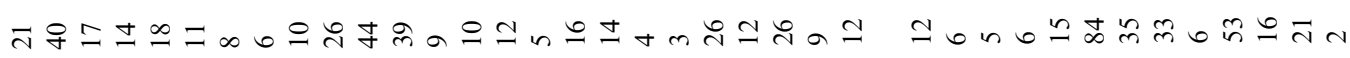

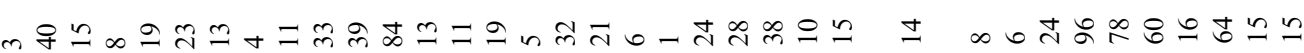

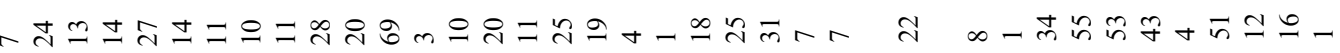

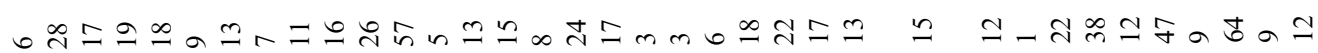

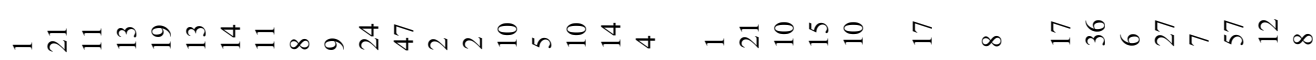

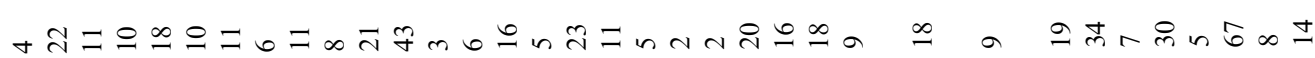
$-\stackrel{\circ}{\sim} \infty \stackrel{\infty}{\rightarrow}$ ニ

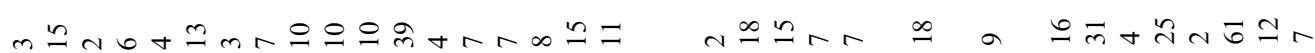
- $⿻ a n \simeq \pm 8$ I

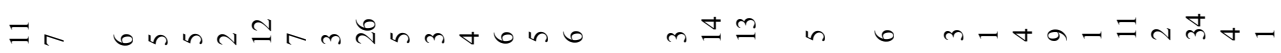

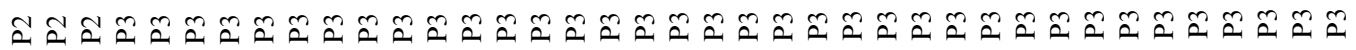

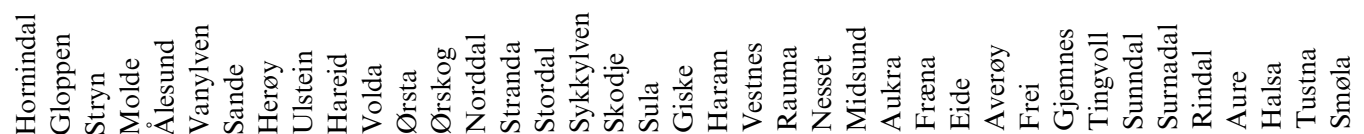


974

Red deer sex ratio and spatial scale
(C) 2000 British Ecological Society Journal of Animal Ecology, 69, 959-974
䮦

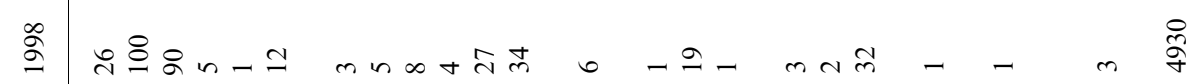
ลू $\infty$ r

よั ڤ̆

茂

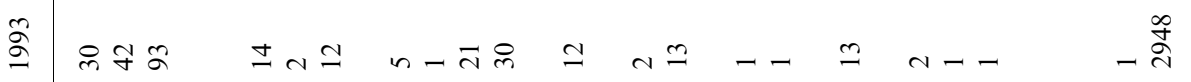
ลั

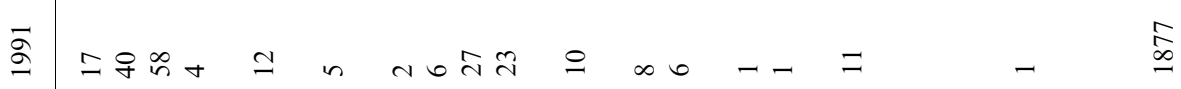

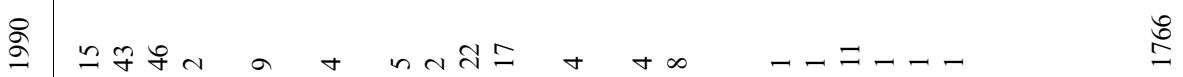

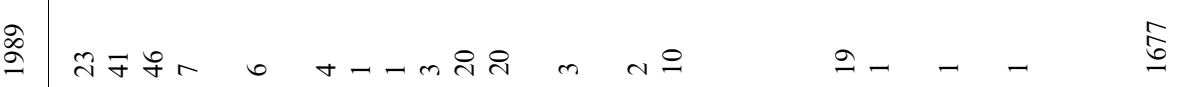
กे

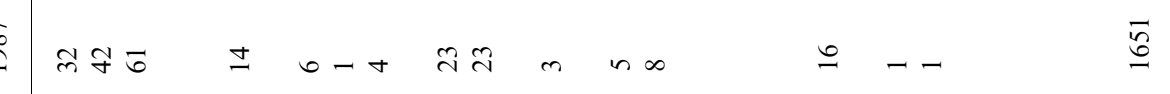

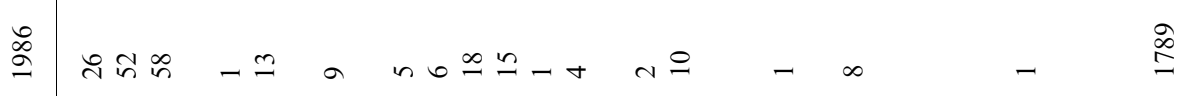

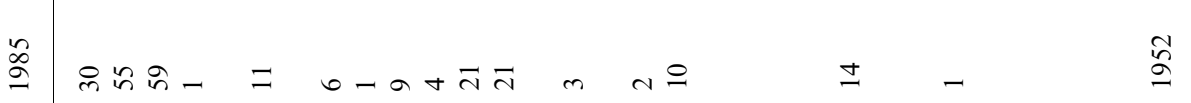
茂

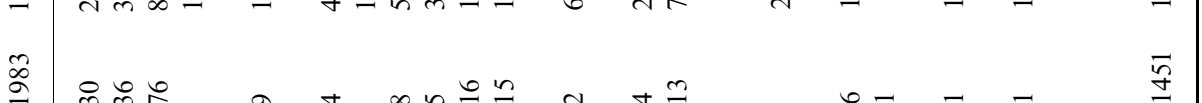
约

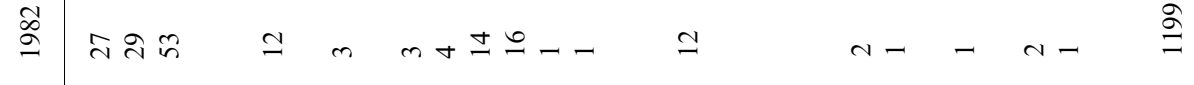
省

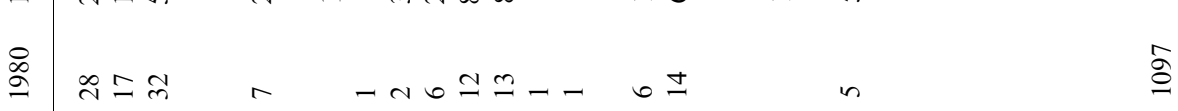

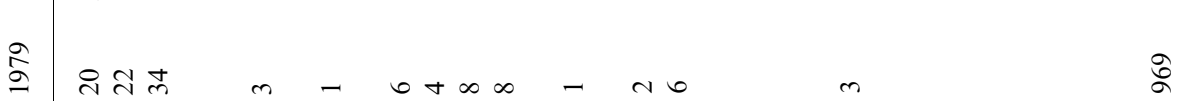

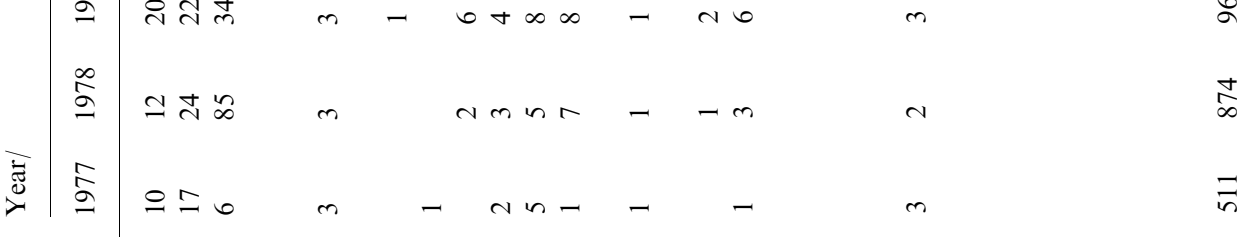

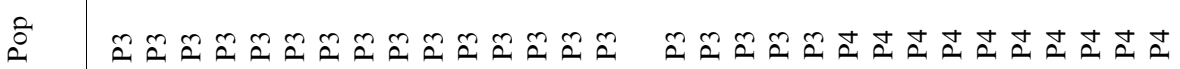

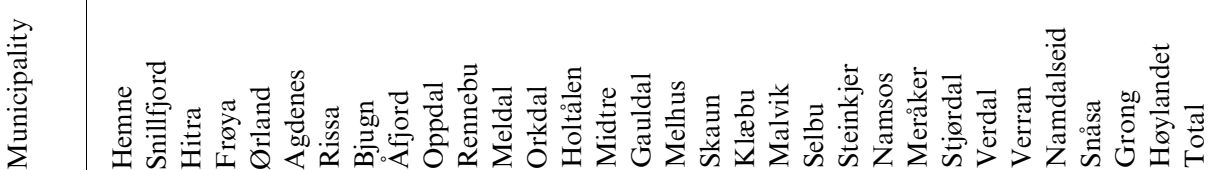

